\title{
Comparison of selected parts of larval morphology in some species of the genus Chironomus (Diptera: Chironomidae) using Scanning Electron Microscope
}

\author{
Andrzej KOWNACKI,${ }^{*}{ }^{*}$ Ewa SZAREK-GWIAZDA,${ }^{1}$ Michał DYKAS,${ }^{2}$ Izabela JABŁOŃSKA-BARNA, ${ }^{3}$ \\ Paraskeva MICHAILOVA ${ }^{4}$ \\ ${ }^{1}$ Institute of Nature Conservation, Polish Academy of Sciences, Kraków, Poland; ${ }^{2}$ Institute of Zoology and Biomedical Research, \\ Jagiellonian University, Kraków, Poland; ${ }^{3}$ Department of Tourism, Recreation and Ecology, University of Warmia and Mazury, \\ Olsztyn, Poland; ${ }^{4}$ Institute of Biodiversity and Ecosystem Research, Bulgarian Academy of Science, Sofia, Bulgaria \\ *Corresponding author: kownacki@iop.krakow.pl
}

\begin{abstract}
Comparison of small sized and weakly chitinized structures such as the labrum (labral setae SI-SIII, labral lamella, tormal bar, pecten epipharings) and the maxilla (maxillary palp, lacinial chaeta) is provided in larvae of Chironomus plumosus, C. balatonicus, C. usenicus C. melanotus, C. acerbiphilus, and C. riparius using Scanning Electron Microscope (SEM). The general morphological structures of the labrum and the maxilla were similar in all of the Chironomus larvae. They differed only in fine details such as labral seta, mainly S I. Seta S I is always plumose on each side and differently figured: elongated in C. balatonicus, C. plumosus, C. melanotus and C. usenicus; rounded in C. acerbiphilus and C. riparius. Some differences were also observed in the shape, length or ratio of lacinial chaetae (LCh I, LCh II). Based on morphological variation in the larvae of some Chironomus species, results indicated that the SEM method is apparently beneficial and useful in the analysis of smaller and weakly chitinized morphological structures such as the labrum and the maxilla.
\end{abstract}

Key words: Chironomus; larvae; morphology; labrum; maxilla; SEM.

Received: December 2017. Accepted: April 2018.

This paper was presented at the $20^{\text {th }}$ International Symposium on Chironomidae, Trento, Italy, 2-8 July 2017. Session: Taxonomy and Systematics.

\section{INTRODUCTION}

The genus Chironomus Meigen has the largest number of species within the Chironomidae family (Fauna Europaea, 2017), yet larvae of most species show slight morphological differences. Important taxonomic features for species identification at the larval stage, which are easily visible under a light microscope, are large, strongly chitinized structures: the mentum and the mandible, and additionally important features are the antenna and the lateral and ventral tubules (Pinder and Reiss, 1983; Cranston, 2010; Orentd and Spies, 2012). However, poorly chitinized structures such as the maxilla and the labrum, which are difficult to recognize under light microscopy, receive little attention and are rarely described (Mozley, 1971). The use of Scanning Electron Microscope (SEM) allows a better understanding of these structures (Kownacki et al., 2015).

The aim of this study was to describe smaller and weakly chitinized morphological structures such as the labrum and the maxilla of some species of Chironomus larvae: C. plumosus Linnaeus 1758, C. balatonicus Devai, Wuelker \& Scholl 1983, C. usenicus Loginova \& Belyanina 1994, C. melanotus Keyl 1961, C. acerbiphilus Toku- naga 1939, and C. riparius Meigen 1804 using a Scanning Electron Microscope.

\section{METHODS}

Larvae of Chironomus were collected from different water bodies of Poland: C. plumosus - from Lake Gardno, a shallow eutrophic, coastal lake, separated by a sandy spit from the Baltic Sea and located in the Slowinski National Park (northern Poland), C. balatonicus - from the Vistula Lagoon (southern part of the Baltic Sea), C. usenicus - from the eutrophic Kortowskie Lake located in the city of Olsztyn. C. melanotus - from Luknajno Lake, shallow, eutrophic, covered with aquatic vegetation, located in the Masurian Landscape Park (north Poland), C. acerbiphilus - from the post-mining, acidotrophic $(\mathrm{pH} 3)$ reservoir located in Luk Muzakowa Landscape Park (western Poland). Larvae of $C$. riparius came from a laboratory strain. The larvae of species collected in their natural habitat were previously identified on the basis of band patterns of their salivary gland chromosomes (Jabońska-Barna 2004; Jabłońska-Barna and Michailova 2006; Jabłońska -Barna et al., 2012, 2013). 
For Scanning Electron Microscope (SEM) the samples were fixed in $2.5 \%$ glutaraldehyde GLU in 0.1 phosphate buffered saline PBS by 2 hours, rinsed with PBS $2 \times 10$ min and dehydrated in graded alcohols. Finally, it was placed in transitional liquid i.e. 100\% acetone and transferred to Critical Point Drier, CPD E3000/E3100 Quorum Technologies. Then it was coated with gold using JFC$1100 \mathrm{E}$ Ion sputter, Jeol. For coating, the materials were placed on the holder with conductive carbon adhesive tabs, Electron Microscopy Sciences. Morphological characters were observed by means of Scanning Electron Microscope (SEM), JSM-5410 operated at accelerating voltages of $15 \mathrm{kV}$ in the Scanning Microscopy Laboratory of the Jagiellonian University (Kownacki et al., 2015). Three larvae of one species were placed on the same slide, and in the case of $C$. acerbiphilus only one larva was used.

The pictures of the labrum and the maxilla from SEM were compared within the Chironomus larvae we studied. Special attention was paid to the structures as labral setae S I-S III (mainly S I), labral lamella (LL), tormal bar (TB), pecten epipharingis (PE), maxillary palp (MP), lacinial chaeta (LCh) and plate X (Pl X). Additional information was obtained by calculating the index $\mathrm{LCh}=\mathrm{LChI} / \mathrm{LChII}$. The information obtained with SEM on the labrum and the maxilla of the Chironomus larvae was compared with Glyptotendipes glaucus larvae (Kownacki et al., 2016).

\section{RESULTS}

Labrum. Seta anteriores (S I) of Chironomus is always plumose on each side, but its shape differs among the species. It is elongated in C. balatonicus, C. plumosus, $C$. melanotus and C. usenicus, while rounded in $C$. acerbiphilus and $C$. riparius. Seta posteriors (S II) is usually single, curved, smooth and without bristles, and seta minuscula (S III) is very small, hair-like (Fig. 1).

Labral lamella (LL) is always arched, its upper edge is smooth, the outer edge is rounded variously, the lower edge is plumose and covered with a row of long daggerlike appendices (Fig. 2).

Tormal bar (TB) is below LL and consist of two arched, sclerotized plates. Pecten epipharyngis (PE) consists of 12-15 single teeth of equal size, or declining towards the lateral edges (Fig. 2).

Maxilla. The maxilla is composed of three major parts: the lacinia (La), galea (G) and maxillary palp (MP). The lacinia (Fig. 3) in all species is sharply ended and triangular, and has two lacinial chaetae (LCh): The first lacinial chaeta (LCh I) is dagger-shaped with smooth edges and the second lacinial chaeta (LCh II) is always shorter than LCh I and lanceolate (for example, C. plumosus) or triangular (for example, C. riparius, C. balatonicus) in shape. The upper edge of LCh II is plumose and the lower is smooth (Fig. 3). Antaxial seta (Aa) is single and slightly curved. The value of the index LCh in the
Chironomus species is the following: C. plumosus - 1.53, C. balatonicus 1.52, C. usenicus 1.67, C. melanotus 1.42 , C. acerbiphilus 1.67, and C. riparius 2.12 .

Maxillary palp (MP) (Fig. 4). The length of the basal segment is greater than its width. Seta A has a different length, for example, it is longer in C. melanotus and $C$. usenicus than in C. acerbiphilus and C.plumosus.

Plate $\boldsymbol{X}(\mathrm{Pl} \mathrm{X})$ in Chironomus larvae consists of a group of bristles situated in the corner between the mentum (M), ventromental plate (VmP) and lacinia (La) (Fig. 5).

\section{DISCUSSION}

Scanning Electron Microscopy has been relatively rarely used to determine the morphological structure of Chironomidae larvae. Earlier studies indicate that the SEM method is very useful in the description of morphology of larvae and species differentiation (Sublette, 1979; Kownacki et al., 2015; Kownacki et al., 2016). Our investigation of Chironomus larvae shows that closely related species can be identified on the basis of lacinial chaetae. For example, the LCh II is elongated in C. plumosus, while triangular in shape in C. usenicus and C. balatonicus. These species are difficult to distinguish on the basis of the external morphology of larvae under the light microscope.

Maxilla Chironomus anthracinus described by Mozley (1971) has the same morphological structure as in the studied Chironomus larvae. Lack of such details as plumose upper edge of LCh II in C. anthracinus is due to lower magnification used in a camera lucida apparatus. However, in a drawing by Mozley (1971) we can see details on the inner side of the maxilla such as the end of lacinia (La) or chaetulae of palpiger (ChP), which results from the use of a light microscope. The SEM image only allows observation of the outer parts of objects.

Our studies and those made by Sublette (1979) show a similar structure of the maxillary palp in the tribe Chironomini. We found that such a detail as the length of seta a (A) may be useful in the differentiation of Chironomus species.

Clear differences were marked in the structure of the maxilla and the labrum between the genus Chironomus and Glyptotendipes (Kownacki et al., 2016). The lower edge of labral lamella in Chironomus ends with very long dagger-shaped appendices, while in Glyptotendipes they are shorter, and blunt at the end. Tormal bar in Chironomus is arched and relatively narrow, while in Glyptotendipes it is triangular. Pecten epipharyngis in Chironomus end with a single row of sharp teeth, while in Glyptotendipes they end with a few rows of teeth of different size, rounded at their tips. Chaetae LCh also show significant differences. In Chironomus, chaeta LCh II is always shorter than chaeta LCh I, while in Glyptotendipes they are of the same length. Another type of structures has lacinia and lacinial chaetae of genus $D i$ crotendipes (Sublette, 1979). That means that the struc- 


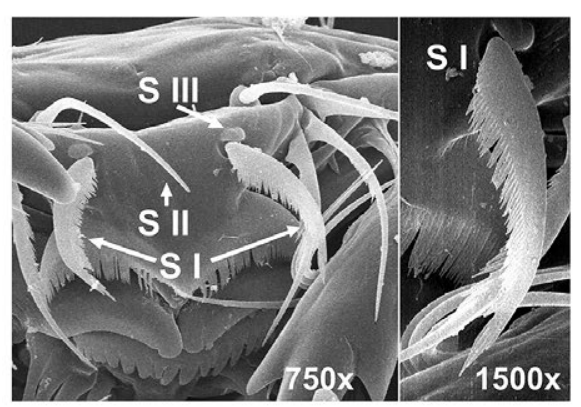

Chironomus balatonicus

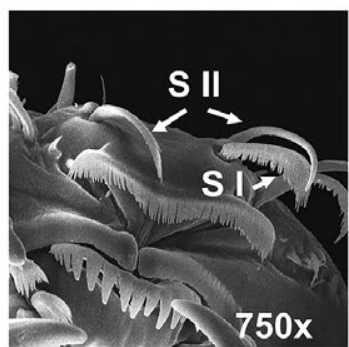

C. usenicus

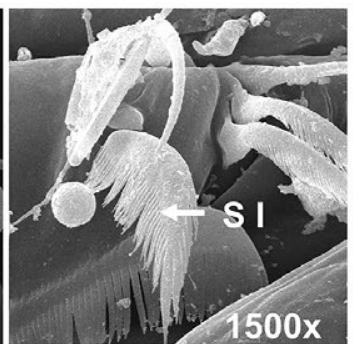

C. melanotus

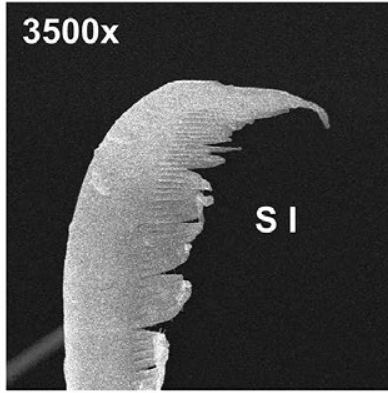

C. plumosus
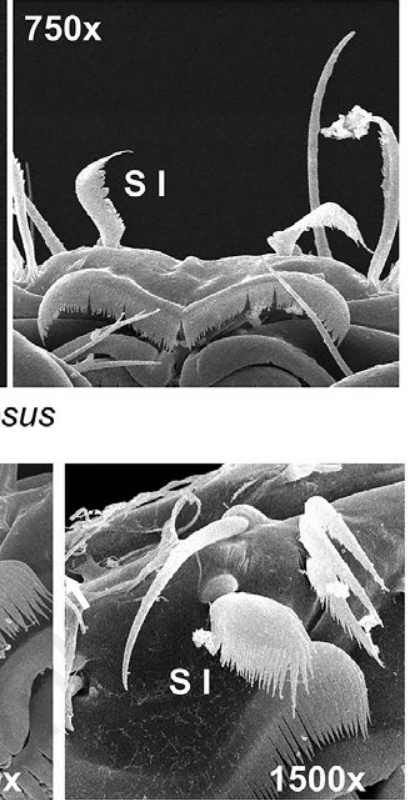

C. riparius

Fig. 1. Chironomus larvae - labral setae. S I, seta anteriores; S II, seta posteriors; S III, seta minuscule.

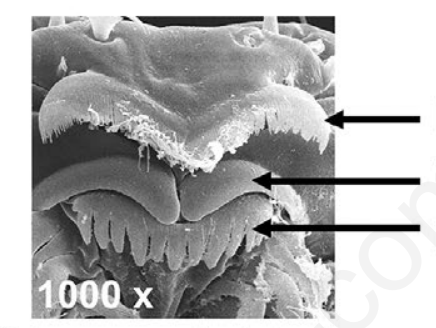

Chironomus balatonicus
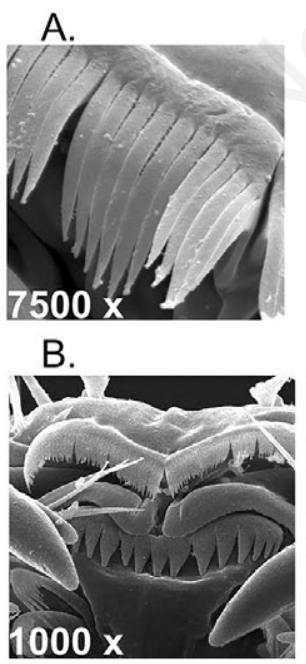

C. plumosus
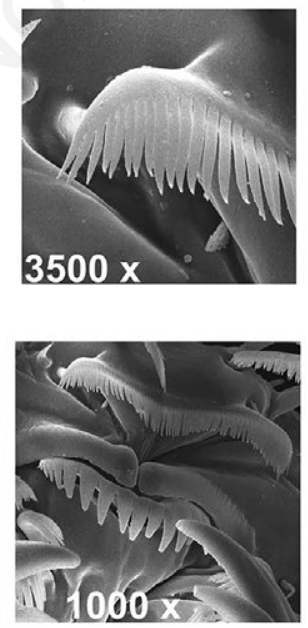

C. usenicus
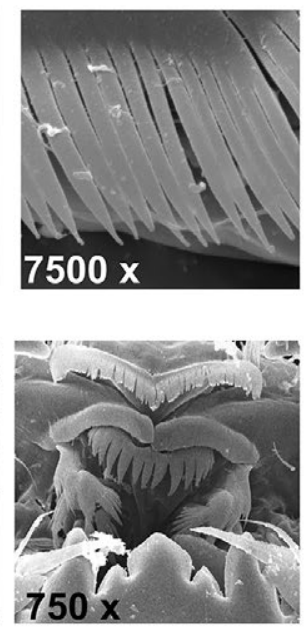
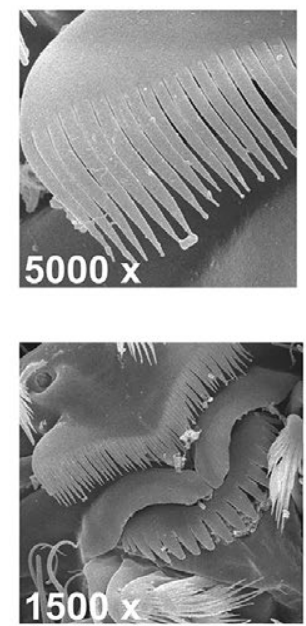

C. acerbiphilus
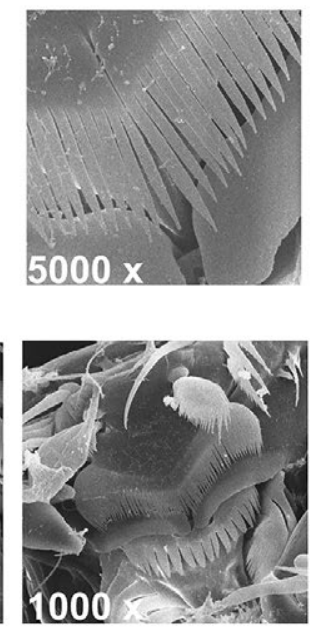

C. riparius

Fig. 2. Chironomus larvae - labrum. A) A fragment of the lower edge of labral lamella. B) Labral lamella, tormal bar, and pecten epipharyngis. 

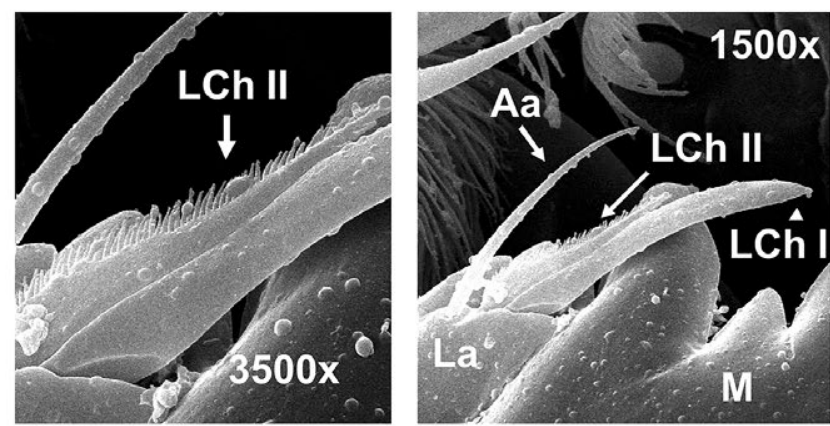

Chironomus plumosus
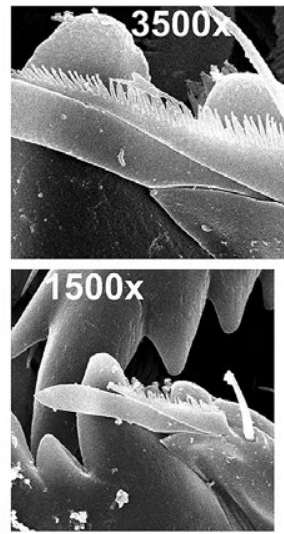

C. balatonicus
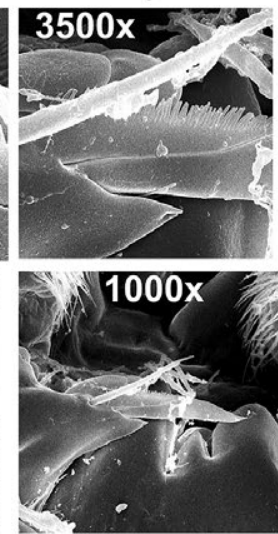

C. usenicus
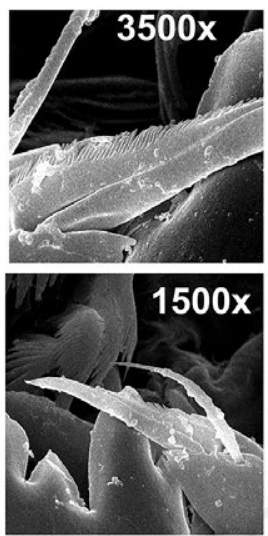

C. melanotus

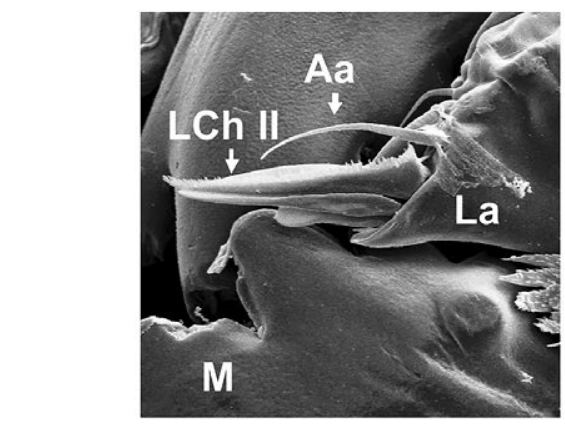

Glyptotendipes glaucus
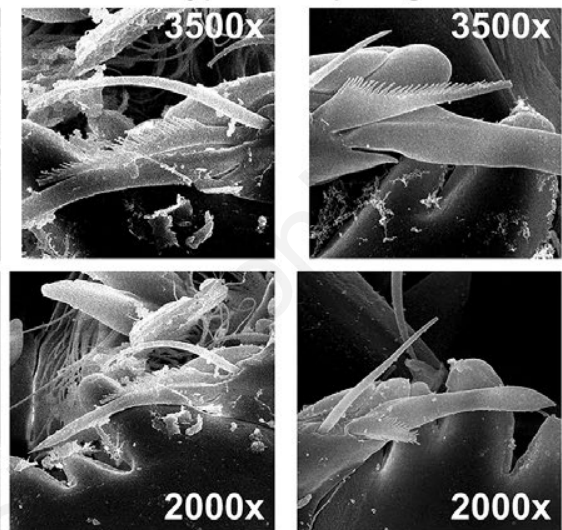

C. acerbiphilus

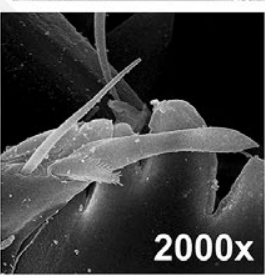

C. riparius

Fig. 3. Chironomus larvae - lacinia. Aa, antaxial seta; La, lacinia; LCh I, lacinial chaeta I; LCh II, lacinial chaeta II; M, mentum.

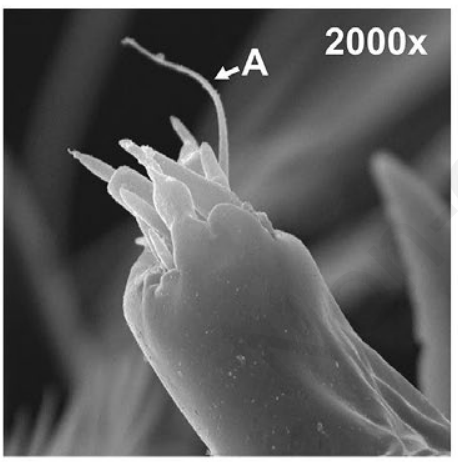

C. plumosus

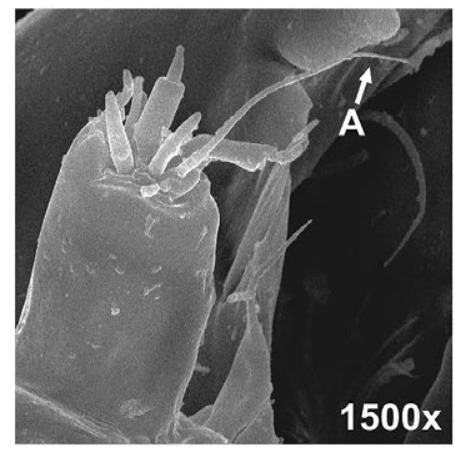

C. melanotus

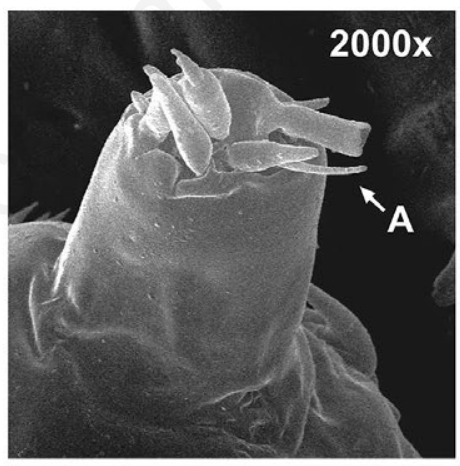

C. balatonicus

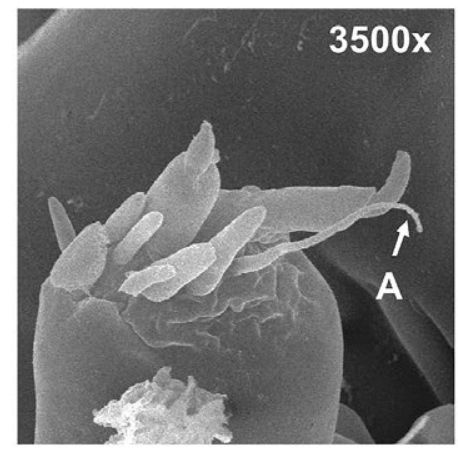

C. acerbiphilus

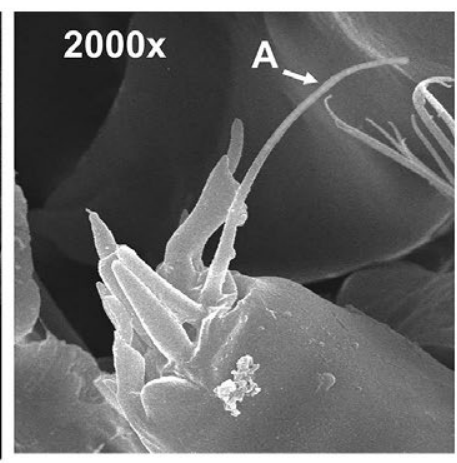

C. usenicus

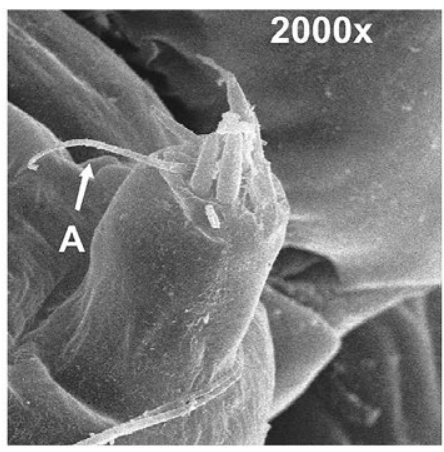

C. riparius

Fig. 4. Chironomus larvae - maxillary palp. A, a seta. 
ture of the maxilla will be a key element in the differentiation of genus Chironomini. Plate X (P1 X) in G. glaucus is in the form of a small plate, on the surface densely covered with tiny spikes (Kownacki et al., 2016), while in our studies of Chironomus they are groups of bristles.

\section{CONCLUSIONS}

In all the investigated material of Chironomus larvae the general morphological structures of both labrum and the maxilla were nearly similar. Only some fine distinctive details can be observed, such like those related to: mor- phology of labral seta (mainly S I); shape, length or ratio of lacinial chaeta; length of seta a (A) of maxillary palp. Results obtained in this study revealed that the SEM method is useful in the analysis of a smaller and weakly chitinized morphological structures such as the labrum and the maxilla of some species.

\section{ACKNOWLEDGMENTS}

The present study was partly supported by the Institute of Nature Conservation, Polish Academy of Sciences in Kraków, Poland as a statutory activity.

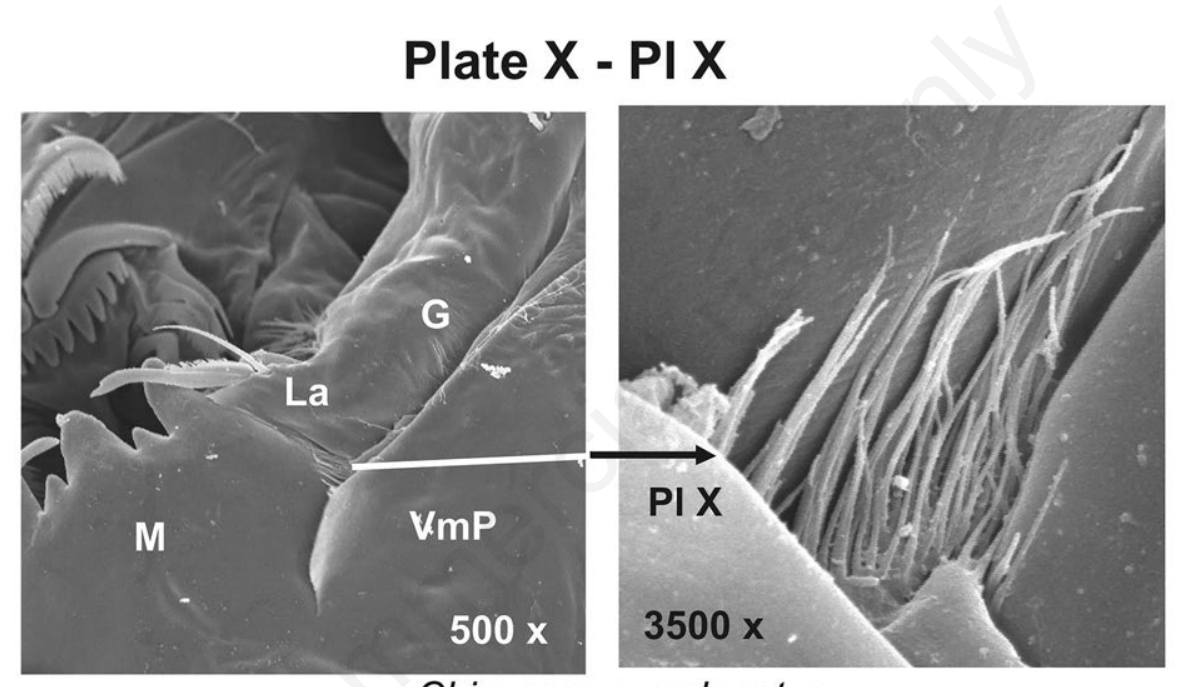

\section{Chironomus melanotus}

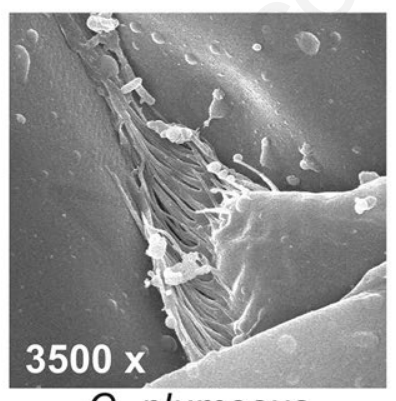

C. plumosus

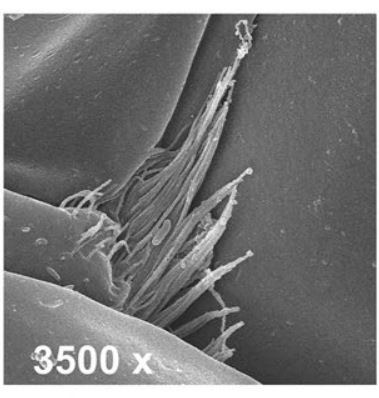

C. balatonicus

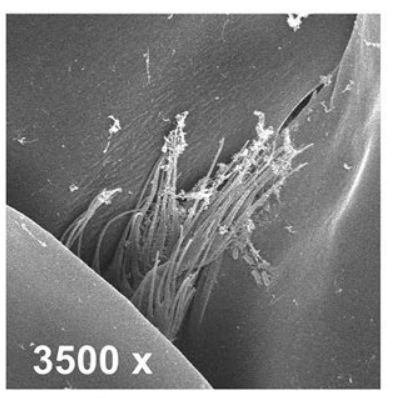

C. riparius
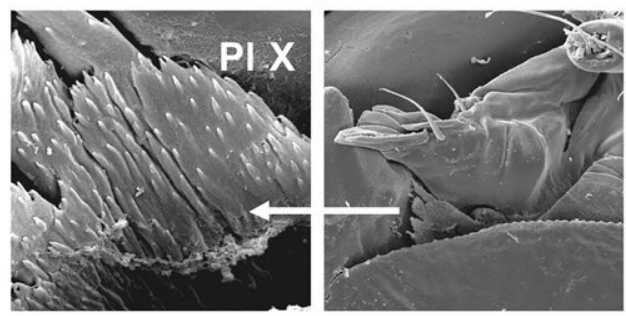

Glyptotendipes glaucus

Fig. 5. Chironomus larvae - plate X (Pl X). G, galea; La, lacinia; M, mentum; VmP, ventromental plate. 


\section{REFERENCES}

Cranston P, 2010. Key to subfamilies Chironomidae. Available from: http://chirokey.skullisland.info/

Fauna Europaea, 2017. Available from: www. faunaeu.org

Jabłońska-Barna I, 2004. New species for Poland: Chironomus balatonicus Devai, Wulker et Scholl, 1983. In: T. Namiotko and T. Sywula (eds.), Biodiversity of benthic environments. BEL Studio, Gdańsk.

Jabłońska-Barna I, Kownacki A, Langton P, Michailova P, 2012. The external morphology of Chironomus (s. str.) acerbiphilus Tokunaga, 1939 a senior synonym of C. crassimanus Strenzke (Diptera, Chironomidae) from Poland. Ann. Zool. 62:633-638.

Jabłońska-Barna I, Michailova P, 2006. Chironomus usenicus Loginova, Belyanina, 1994 (Diptera, Chironomidae) a species cytotaxoinomically identified from Kortowskie lake, Poland. Polish J. Nat. Sci. 2:927-937.

Jabłońska-Barna I, Szarek-Gwiazda E, Michailova P, 2013. Environmental agents in Lake Luknajno (Poland) affect genome of Chironomus melanotus Keyl, 1961 (Diptera, Chironomidae) - a new species for Polish fauna. Oceanol. Hydrobiol. St. 42:164-172.
Kownacki A, Szarek-Gwiazda E, Woźnicka O, 2015. The importance of scanning electron microscopy (SEM) in taxonomy and morphology of Chironomidae (Diptera). Eur. J. Environ. Sci. 5:41-44.

Kownacki A, Woźnicka O, Szarek-Gwiazda E, Michailova P, 2016. Larva of Glyptotendipes (Glyptotendipes) glaucus (Meigen 1818) (Chironomidae, Diptera) - morphology by Scanning Electron Microscope (SEM), karyotype, and biology in laboratory conditions. Zootaxa 4169:555-570.

Mozley SC, 1971. Maxillary and premental patterns in Chironominae and Orthocladiinae (Diptera: Chironomidae). Can. Entomol. 103:298-305.

Orendt C, Spies M, 2012. Chironomus Meigen (Diptera: Chironomidae). Key to the larvae of importance to biological water analysis in Germany and adjacent areas. Ehnert \& Blankeburg, Leipzig: 24 pp.

Pinder LCV, Reiss F, 1983. The larvae of Chironominae (Diptera: Chironomidae) of the Holarctic region - Keys and diagnosis. Entomol. Scand. Suppl. 19:293-435.

Sublette JE, 1979. Scanning electron microscopy as a tool in taxonomy and phylogeny of Chironomidae (Diptera). Entomol. Scand. Suppl. 10:47-65. 